\title{
Variation in Interlibrary Loan Use by University at Albany Science Departments
}

\section{Eleanor Gossen and Sue Kaczor}

\begin{abstract}
Interlibrary loan use patterns for scientists at the University of Albany, SUNY, were determined by analyzing one year's worth of filled interlibrary loan (ILL) requests for journal articles. Differences were observed among scientific disciplines in their reliance on ILL to obtain journal articles, with biology requesting the most (54\%) and geology the least (1\%). Most requests were made for only 1 or 2 articles. Individual journal titles were generally requested only once (79.9\%). The majority of requests were for journal articles published in the ten years prior to the study, although $21 \%$ were for earlier materials. At the University at Albany, scientists are actively using electronic indexing and abstracting tools to identify journal articles (48\%), although printed and other resources remain an important component of identification (32\%).
\end{abstract}

\begin{abstract}
A
budgets have become tighter and as periodical prices have risen in recent years, academic libraries have been forced to reduce their periodical holdings and rely increasingly on interlibrary borrowing to fulfill their patrons' needs for journal articles. This has been particularly true in the sciences, where journal price increases over the last 5 years have generally been on the order of $10-15 \%$ per year (Ketcham and Born 1996). Because science titles are among the most expensive, they have become likely targets for cancellation, causing concern on the part of science faculty and students, who fear that they will not be able get the information they need in a timely manner.

Numerous authors have written about patterns of expenditures in libraries, the
\end{abstract}

impact of rising serials prices on library budgets, and the cost-effectiveness of journal subscriptions (see, for example, Barschall 1988; Hamaker 1989; Ketcham and Born 1996; Kingma 1996). Hamaker (1994) found that a third of the chemistry titles subscribed to by the Louisiana State University Libraries were of interest to only a single faculty member and that the chemistry faculty was generally receptive to substituting document delivery for ownership of many titles. Herzog (1993) carried out a use study at the University at Albany, State University of New York (SUNY), of its periodical collection in 1991-92, which provided information on relative use by department and showed that there were many titles that were rarely used. This information was useful

ElEANOR GOSSEN (EAG97@cnsvax albany.edu) is Social Sciences Bibiliographer, University at Albany, SUNY. SUE KACZOR (skaczor@cnsvax.albany.edu) is Science Bibilographer, University at Albany, SUNY. Manuscript received July 15, 1996; accepted for publication September 25, 1996. 
in drawing up a list of titles for cancellation in 1992, and has in fact led to an experiment for substituting document delivery for ownership with the biology department there. In discussions about alternatives to ownership for the low-use titles identified by Herzog, it became apparent that very little was known about Interlibrary Loan (ILL) use patterns. It was felt that better information about existing patterns of requests for science journal articles in particular could help inform decisions about journal collection decisions.

ILL transactions are an integral part of the access versus ownership dilemma confronting academic libraries. Because ILL transactions have become safety nets for libraries, enabling them to meet patrons' information needs in spite of shrinking resources, such transactions merit evaluation. This study, focusing on a year's worth of requests for journal articles, was undertaken to describe ILL behavior of faculty, staff, and students in 7 science departments (atmospheric science, biology, chemistry, computer science, geology, mathematics and statistics, and physics) at the University at Albany. Some of the questions that we try to address in this study are: Is ILL used more frequently by people in some scientific disciplines than in others?, Is there any relationship between the amount of money spent on periodicals in a discipline and the number of article ILL requests by patrons in that discipline?, Are most ILL requests for very recent articles or is there a demand for older materials?, and How do patrons find out about articles? The answers to such questions can provide useful information to subject bibliographers and library administrators and enable them to make well-informed decisions about how to invest their resources.

\section{BACKGROUND}

Authors of various studies have recently published reports on ILL use in a specific discipline or a small group of scientific disciplines. Ferguson and Kehoe (1993) studied ILL and commercial document delivery requests made by faculty and graduate students in biology, physics, and electrical engineering at Columbia University. In 1994, Kingma (1995) surveyed University at Albany patrons throughout the university who requested science articles through ILL, and analyzed their use over time as well as by patron status (i.e., faculty, graduate student, undergraduate). He did not include information about variation among individual disciplines within the sciences. Besides this, no recent articles that compare ILL use by discipline across the spectrum of the hard sciences were identified.

Several researchers have studied the information-seeking behavior of scientists, including their use of citations. Brown (1956) examined citation patterns in selected scientific disciplines. Devin (1989) studied the extent to which researchers in a variety of fields cited the journal literature in their publications. Hallmark (1994) reported on how scientists from a variety of disciplines found out about and retrieved articles that they cite in their publications. These studies support the authors' belief that access to literature, whether in the library or elsewhere, is and is likely to remain an important concern.

\section{METHODOLOGY}

To examine what scientists actually request through ILL, filled-out ILL request forms for articles submitted by faculty, staff, and students of the 7 previously mentioned University at Albany science departments were separated out from those submitted by people from other departments. The following information was extracted from these forms: requester's name, department, status, journal citation, source of citation, source of filled request, date of request, and date of receipt of article. The study period encompassed one year, from May 1, 1993, through April 30, 1994. Articles of a scientific nature that were requested by patrons who identified themselves as being from a nonscientific discipline (i.e., for this study, all departments other than the 7 specific departments) were not included in the study because the focus of this study 
TABLE 1

USER Population (FTEs) in THE Sciences Compared to Total User Population 1993

\begin{tabular}{llccccccc}
\hline \hline & \multicolumn{2}{c}{ Faculty } & \multicolumn{2}{c}{ Graduate Students } & \multicolumn{2}{c}{ Students } & \multicolumn{2}{c}{ Total } \\
& No. & $\%$ & No. & $\%$ & No. & $\%$ & No. & $\%$ \\
\hline Sciences & 111 & 12 & 357 & 10 & 2,215 & 21 & 2,683 & 18 \\
Campus & 928 & & 3,604 & & 10,511 & & 15,043 & \\
\hline
\end{tabular}

was on the information-seeking behavior of scientists. Requests for nonscience materials made by scientists were included. If a request was for a title clearly on a scientific topic but there was no departmental affiliation indicated, it was treated as if it were a request made by a scientist. The data were entered into an Enable database and analyzed for trends. Data on full-time equivalent (FTE) faculty and students in the university as a whole and in individual science departments were obtained from the university's Office for Institutional Research. Data on staff by FTE are no longer kept by the university, so those figures were unavailable.

\section{ILL USE BY SCIENTISTS}

Of the 4,655 requests for articles that were filled by the ILL office during the 1993-94 academic year, 412 requests (approximately $9 \%$ ) were made by faculty, staff, or students in the sciences. Given that the sciences represent roughly $18 \%$ of the FTE faculty and students at of the University at Albany (see table 1), scientists requested journal articles from ILL during this year less often than would be expected if one assumed that there were a direct correlation between number of faculty and number of ILL requests. It is not clear whether this results from the sciences having sufficient library journal collections, members of the scientific community having more sources of information outside the library, the fact that scientists do not use periodicals outside their area of specialization, the fact that they cannot wait two or more weeks to receive materials, or some combination of these. Hallmark (1994) found that, for the fields of physics, chemistry, biology, mathematics, and geology, scientists rely heavily on nonlibrary sources (reprints, preprints, photocopies from colleagues, and personal subscriptions) for copies of articles in journals not found in their libraries. This is probably the case at the University at Albany also and may help explain the relatively low use of ILL by scientists on campus.

There is some evidence that scientists at the University at Albany request articles via ILL relatively less often than might be expected because they have more extensive journal collections than do people in some other fields. All periodicals in the University Libraries' collections are assigned a fund code that corresponds to an academic department. Periodicals assigned to science departments represent $26 \%$ of the collection and $68 \%$ of the periodical budget. Figures from a use study carried out during the 1991-92 academic year at the University Libraries showed that, for current subscriptions, science periodicals accounted for $22 \%$ of total in-library periodical use. This is somewhat higher than would be expected if there were a direct correlation between percentage of FTEs (18\%) in the sciences and percentage of use. Scientists at the University at Albany may be able to find more of the articles they need in the library than can people in other disciplines and therefore have less need to use ILL.

Another possible explanation for the relatively lower use of ILL by scientists at Albany is that the sciences have a smaller percentage of graduate students than does the campus as a whole. In 1993-94, $13 \%$ of the FTEs in the sciences were graduate students (representing $10 \%$ of the total campus graduate student population), whereas graduate students made 
TABLE 2

Percentage of FTEs and Graduate Students in Science Departments

\begin{tabular}{lrrrrr}
\hline \hline Department & \multicolumn{2}{c}{ \%Total FTEs } & \multicolumn{2}{c}{$\begin{array}{c}\text { \% Grads } \\
\text { in Dept. }\end{array}$} & \% ILL Requests \\
\hline Atmospheric Sciences & 9 & $(232.5)$ & 15 & 2 & $(7)$ \\
Biology & 23 & $(604.5)$ & 10 & 54 & $(221)$ \\
Chemistry & 13 & $(351.5)$ & 10 & 20 & $(82)$ \\
Computer Science & 14 & $(362.5)$ & 17 & 3 & $(13)$ \\
Geology & 3 & $(91.5)$ & 12 & 1 & $(5)$ \\
Mathematics \& Statistics & 25 & $(661.5)$ & 12 & 4 & $(13)$ \\
Physics & 14 & $(378.5)$ & 21 & 10 & $(43)$ \\
Total & & $(2,682.5)$ & & & \\
\hline
\end{tabular}

up $24 \%$ of the campus population as a whole. Kingma (1995, figure 4.1) found that $62 \%$ of ILL requests were submitted by graduate students, so it is reasonable to argue that departments with a smaller percentage of graduate students can be expected to submit fewer ILL requests than departments with a high percentage of graduate students. This theory, however, is contradicted by the evidence for individual departments within the sciences. The departments that generated the most ILL requests (biology and chemistry) had the lowest percentages of graduate students (see table 2). Since professional research staff were responsible for a considerable number of the ILL requests from the biology and chemistry departments, these figures may reflect active faculty research programs in which research staff rather than graduate students carry a lot of the burden for gathering information.

\section{USE BY DEPARTMENT}

There seems to be little relationship between ILL activity and the amount of support provided by the library for a discipline. For example, $33 \%$ of the science journal titles in the library and $30 \%$ of the total cost of science journals were in biology, yet biologists made $54 \%$ of the ILL requests. On the other hand, $10 \%$ of the science journals are in geology, but geologists made only $1 \%$ of the ILL requests.
Likewise, $16 \%$ of the science journals in the library are in the area of mathematics, but mathematicians made only $4 \%$ of the ILL requests (see table 3 ). There are several possible explanations for these phenomena. They may be due to different patterns of information use in the various departments. In a study of the reliance of various disciplines on the serial literature, Devin (1989) reported that citations to journal articles (as opposed to monographs) ranged from $76.8 \%$ in mathematics to $93.6 \%$ in chemistry. While interesting, these numbers may not accurately reflect ILL use in these areas. For example, biologists may need to use a greater variety of periodical articles in their research than do computer scientists or geologists, a need that may be addressed through ILL. Or perhaps some fields rely more heavily on alternative methods of gaining access to information that bypass the library, such as preprints of articles or communication with colleagues. Of note, Ferguson and Kehoe (1993) also found that biology had the heaviest use of ILL among the disciplines they studied, which were biology, physics, and electrical engineering.

Differences in ILL use might also be explained by the different sizes of the departments, but there seems to be little correlation between the size of a department and the percentage of ILL requests filled for that department (see table 2). The department of mathematics and sta- 
TABLE 3

INTERLIBRARY LOAN REQUESTS COMPARED TO LIBRARY SUPPORT

\begin{tabular}{lrrrrr}
\hline Department & No. ILL Req. & \% ILL Req. & No. Titles in Lib. & \% Sci. Titles & \% Sci. Cost \\
\hline Atmospheric Sciences & 7 & 2 & 71 & 7 & 5 \\
Biology & 221 & 54 & 361 & 33 & 30 \\
Chemistry & 82 & 20 & 134 & 12 & 20 \\
Computer Science & 13 & 3 & 57 & 5 & 3 \\
Geology & 5 & 1 & 112 & 10 & 6 \\
Mathematics \& Statistics & 15 & 4 & 176 & 16 & 11 \\
Physics & 43 & 10 & 118 & 11 & 23 \\
General Science & - & - & 68 & 6 & 2 \\
Unknown Dept. & 26 & 6 & - & - & - \\
\hline
\end{tabular}

tistics accounts for $25 \%$ of the FTEs in the sciences, and yet made only $4 \%$ of the ILL requests. Biology accounts for $23 \%$ of the FTEs, yet made $54 \%$ of the requests. Chemistry, with only $13 \%$ of the FTEs, made $20 \%$ of the ILL requests. Geology, with the smallest percentage of FTEs $(3 \%)$, also made the smallest number of requests $(1 \%)$. There is no clear pattern here.

Data from the 1991-92 use study mentioned above show that the science departments that were the heaviest users of ILL (biology and chemistry) also accounted for the highest number of uses of the in-house collection of current peri- odicals. Physics and computer science, on the other hand, used both the in-house collection and ILL less than would be expected, given the number of users in those departments. In fact, there is a surprisingly good correlation between high in-house journal use and high ILL use in the sciences (see table 4), but little correlation between percentage of FTEs and percentage of use of both in-house collections and ILL. More departmental personnel do not necessarily generate more use.

If these patterns prove consistent from year to year, they may suggest a reevaluation of collection development policies

TABLE 4

INTERLIBRARY LOAN REQUESTS COMPARED TO IN-LIBRARY USE

\begin{tabular}{lcccc}
\hline Department & $\begin{array}{c}\text { In-House No } \\
\text { Uses 1991-92 }\end{array}$ & $\begin{array}{c}\text { In-House \% Use } \\
\text { 1991-92 }\end{array}$ & \% ILL & \% FTEs \\
\hline Atmospheric Sciences & 1,404 & 4 & 2 & 9 \\
Biology & 12,927 & 38 & 54 & 23 \\
Chemistry & 6,654 & 19 & 20 & 13 \\
Computer Science & 1,655 & 5 & 3 & 14 \\
Geology & 1,577 & 5 & 1 & 3 \\
Mathematics \& Statistics & 2,067 & 6 & 4 & 25 \\
Physics & 3,132 & 9 & 10 & 14 \\
Unknown Dept & - & - & 7 & - \\
General Science & 5,031 & 15 & - & - \\
\hline
\end{tabular}


and the allocation of funds among departments. During the year of the study, there appeared to be differences in the ways different disciplines in the sciences find and use information. The amount of use of ILL did vary by department, with those in the biological sciences and chemistry demonstrating greater use. Faculty and students in other scientific disciplines either may not need access to periodical articles outside their areas of specialty or may rely more heavily on other sources of information for their research needs.

\section{USE BY TITLE}

During the 1993-94 academic year, scientists at the University at Albany requested 412 articles from 291 different periodical titles. Of these journal titles, $232(79.7 \%)$ were requested only once, while 59 were requested more than once. Table 5 shows the frequency of requests for articles from the same journal. Only 6 titles were requested more than 5 times, the point at which copyright issues emerge. These results are similar to those reported by Ferguson and Kehoe (1993), who found that $72 \%$ of their requests were for articles from titles requested only once during their study.

\section{TABLE 5}

FREQUENCY OF REQUESTS FOR THE SAME JOURNAL DURING THE STUdY PERIOD

\begin{tabular}{cccc}
\hline & No. Titles & \% Total & $\begin{array}{c}\text { No. Times } \\
\text { Requested }\end{array}$ \\
\hline 232 & 79.7 & 1 \\
34 & 13.7 & 2 \\
12 & 3.1 & 3 \\
3 & 1.0 & 4 \\
& 1 & 0.3 & 5 \\
& 0 & 0 & 6 \\
& 3 & 1.0 & 7 \\
& 1 & 0.3 & 10 \\
& 1 & 0.3 & 12 \\
Total & 1 & 0.3 & 13 \\
& 288 & & 409 \\
\hline
\end{tabular}

Do articles from the same journals get requested repeatedly year after year? All of the titles that were requested by scientists in the 1993-94 academic year were checked against the records of requests for articles that were published less than 5 years previous to the request, data which the ILL Department keeps for copyright law compliance purposes. These files reflect ILL requests dating back to 1991. Although the files do not contain information on requests made for articles that were more than 5 years old at the time of request, they do give a good indication of whether the same titles get requested year after year. As it turns out, of the 291 periodical titles that were requested in 1993 $94,73 \mathrm{had}$ also been requested in previous years. Again, of the 291 titles, 25 were requested only in 1993-94 and only 39 titles were requested between 2 and 10 times during the years for which we have records, indicating that there is not great repeat demand for most of the journals that are requested through ILL. However, 8 titles were requested between 11 and 22 times, and 1 (Pediatrics) was requested 54 times during those 5 years! Given that Pediatrics is not an expensive journal ( $\$ 130$ /year in 1995), it is clearly neither cost-effective nor efficient to rely on ILL to supply this journal, particularly when the copyright fees for more than 5 requests in a given year are included. On the other hand, while the European Journal of Pharmacology was requested 14 times, it is very expensive $(\$ 3,874$ /year in 1995) and would have to be used considerably more than this to make it costeffective to subscribe to it. Again, this information has implications for collection development and suggests that ILL request patterns should be carefully monitored for cost effectiveness.

\section{USE BY INDIVIDUALS}

Is use of ILL spread fairly evenly throughout the scientific user population, or is it used heavily by a few individuals and little or not at all by the majority of the population? The 412 requests were submitted by 128 individuals, or roughly $5 \%$ of the science community. Analysis showed that 69 
TABLE 6

FREQUENCY OF ILL REQUESTS BY INDIVIDUALS

\begin{tabular}{lccccccc}
\hline \hline & Faculty & $\begin{array}{c}\text { Graduate } \\
\text { Students }\end{array}$ & $\begin{array}{c}\text { Undergrad. } \\
\text { Students }\end{array}$ & Staff & \multicolumn{2}{c}{ Other } & \multicolumn{2}{c}{ Total } \\
No. Reg. & No. & No. & No. & No. & No. & No. & $\%$ \\
\hline 1 & 21 & 27 & 12 & 7 & 2 & 69 & 54 \\
$2-5$ & 12 & 22 & 8 & 0 & 0 & 42 & 33 \\
$6-10$ & 5 & 6 & 0 & 1 & 0 & 12 & 9 \\
$11-15$ & 2 & 0 & 0 & 0 & 0 & 2 & 2 \\
$>15$ & 2 & 0 & 0 & 1 & 0 & 3 & 2 \\
$\quad$ Total & & & & & & 128 & \\
\hline
\end{tabular}

people requested only 1 article during the study period, and 42 requested 2 to 5 articles. Twelve people made between 6 and 10 requests, and 5 individuals requested 11 or more articles; these 5 individuals accounted for 131 requests, just over $30 \%$. Of these 5 individuals, one requested 11 articles, one 12 , one 24 , one 35 , and one 49 (see table 6). Four of these heavy users were faculty members and one was a staff member. It is interesting to note that the three heaviest users of ILL have research interests that are peripheral to the core interests of their departments as reflected in the University Libraries' collection development policies. The individual who requested 24 articles conducts research in an area that is not a primary research area at the institution and made most of his requests for articles that were published more than 20 years ago, many in journals that have ceased publication. Many of the articles requested by the person who requested 35 articles are from Japanese-language journals, which would not be useable by most of the user population even if the library owned them. The individual who requested 49 articles conducts research on a medical topic and needs articles from medical journals that are not collected since the University at Albany does not have a medical school.

In the cases of the titles that were requested 12 and 13 times, all the requests within each title were made by the same individual. In the majority of cases of multiple requests for articles from a single title, the requests were made by one individual on the same day. This suggests that scientists tend to do bibliographic research in batches, searching a topic, journal title, or author in several years of printed indexes or databases for citations, determining what they could get locally, and submitting multiple ILL requests at one time.

ILL requests appear to be an important source of journal articles for a few individuals who have research interests requiring resources outside the primary collection development focus at the University at Albany. They serve as a supplementary source of information for others who request 1 or 2 articles a year, but most of the scientists on campus seem to get the information they need in the local collection or to go to nonlibrary sources for information not held by the library. Similar results were found by Hallmark (1994).

\section{Use by Year of Publication}

Analysis of ILL transactions for people in the sciences by year of publication provides insights for both collection development and the ILL department. The data were broken down by year of publication and department of requester (see table 7). It is interesting to note that even though we included requests submitted and filled until April 30, 1994, only $1 \%$ of the requests were actually for articles published in 1994. In all probability, the most pressing current awareness needs are met largely by personal, library, or colleague subscriptions. In addition, there is a lag 
TABLE 7

YEAR OF PUBLICATION BY DEPARTMENT

\begin{tabular}{lcrrrrrrrrrr}
\hline \hline & Atm & Bio & Chm & Csi & Geo & Mat & Phy & \multicolumn{2}{c}{ Unk } & \multicolumn{2}{c}{ Total } \\
Date & No. & No & No. & No. & No. & No. & No. & No. & No. & $\%$ \\
\hline 1994 & 0 & 3 & 0 & 0 & 0 & 1 & 0 & 1 & 5 & 1 \\
$1984-93$ & 3 & 170 & 73 & 8 & 3 & 8 & 43 & 21 & 320 & 78 \\
$1974-83$ & 0 & 13 & 7 & 0 & 2 & 3 & 7 & 3 & 35 & 9 \\
$1793-1973$ & 4 & 35 & 1 & 5 & 0 & 3 & 2 & 1 & 51 & 12 \\
$\quad$ Total & & & & & & & & & 411 & \\
\hline
\end{tabular}

-Atm = Atmospheric Sciences, Bio $=$ Biology, Chm = Chemistry, Csi $=$ Computer Science, Geo $=$ Geology, Mat = Mathematics \& Statistics, Phy = Physics, Unk = unknown departmental affiliation.

between the time when an article is published and when it appears in indexing services or is referred to in journal articles; this is likely to be an important factor in the low numbers of requests for current year publications.

The publication date for the majority of ILL requests $(78 \%)$ ranges from 1984 to 1993 , roughly the ten-year period prior to the study. This was to be expected, given the strong dependence of the sciences on recent information. Nine percent of the requests were published from 1974 to 1983 , and $12 \%$ predate those (1793 to 1973). Looked at from another perspective, however, $21 \%$ of the requests were for articles published more than ten years before the study. We were surprised to find that there is still a considerable demand for titles published over 20 years ago (12\%) (see table 7 ).

\section{Source of Citation}

How do people find out about articles that they request on ILL? Although the ILL form stated that this information was "mandatory," $16 \%$ of the forms examined did not contain this information. The single-largest category, CD-ROM, was the source of $32 \%$ of the requests (see table 8 ). The next highest ranked categories are None Listed (16\%), Online (16\%), and Article $(15 \%)$. When CD-ROM is combined with the Online category $(16 \%), 48 \%$ of the requests were located using electronic technology (see table 8). In contrast, $32 \%$ of the citations were derived from so-called tradi- tional format sources. These included the categories Article (15\%), Paper Index (9\%), Book (4\%), and Personal Communication $(2 \%)$. This pattern is most evident in requests for articles written in the ten years prior to the study (see table 9). Looking only at the ILL requests for journal articles that were published from 1793 to 1973 , traditional formats are much more important. Of the 51 requests for documents more than 20 years old, only $6 \%$ of the citations were identified using electronic sources, while $73 \%$ came from the traditional sources listed above. The number of citations derived from

TABLE 8

Where Cited by Frequency

\begin{tabular}{lcc}
\hline Source of Citation & Frequency & $\%$ \\
\hline Traditional format & 130 & 32 \\
$\quad$ Article & $(63)$ & $(15)$ \\
Paper index & $(39)$ & $(9)$ \\
Book & $(17)$ & $(4)$ \\
$\quad$ Personal & $(10)$ & $(2)$ \\
$\quad$ communication & 196 & 48 \\
Electronic format & $(130)$ & $(32)$ \\
$\quad$ CD-ROM & $(66)$ & $(16)$ \\
Online & 67 & 16 \\
None listed & 11 & 3 \\
Index & 8 & 2 \\
Other & & \\
\hline
\end{tabular}

-Index = index of unknown format. 
TABLE 9

Year of Publication by Source of Citation

\begin{tabular}{lrrrrrrrrrrr}
\hline \hline & \multicolumn{3}{c}{ Electronic } & \multicolumn{3}{c}{ Traditional } & \multicolumn{2}{c}{ Index* } & \multicolumn{2}{c}{ Other } & \multicolumn{2}{c}{ None } & Total \\
Date & \multicolumn{1}{c}{ No. } & \multicolumn{1}{c}{$\%$} & \multicolumn{1}{c}{ No. } & $\%$ & No. & $\%$ & No. & $\%$ & No. & $\%$ & No. \\
\hline 1994 & 3 & 6 & 0 & 0 & 0 & 0 & 1 & 20 & 1 & 29 & 5 \\
$1984-93$ & 182 & 57 & 76 & 24 & 10 & 3 & 6 & 2 & 47 & 15 & 320 \\
$1974-83$ & 8 & 23 & 17 & 49 & 1 & 3 & 0 & 0 & 9 & 26 & 35 \\
$1793-1973$ & 3 & 6 & 37 & 73 & 0 & 0 & 1 & 2 & 10 & 20 & 51 \\
Total & 196 & 48 & 130 & 32 & 11 & 3 & 8 & 2 & 67 & 16 & 411 \\
\hline
\end{tabular}

-Index = index of unknown format.

electronic sources increases to $23 \%$ in the 1974-83 time period, and rises to $57 \%$ in 1984-93. For citations from traditional sources, the number decreases to $49 \%$ for articles published in 1974-83 and then to $24 \%$ for $1984-93$ articles.

Although there is a heavy use of electronic technology to locate citations, the combined traditional sources are still a valuable tool for people in the sciences to locate citations of importance, especially for earlier materials. This can be accounted for in part by the fact that most of the major electronic sources do not index articles over 20 years old.
These findings differ from those reported by Hallmark (1994), who asked scientists how they became aware that journal articles existed. She reported that the primary sources of awareness were personal contacts and references in the literature. Databases (online or CD-ROM), traditional abstracting and indexing services, and current awareness services represented a much smaller percentage of information sources for her population. She was, however, surveying established scientists who had published in prestigious journals. These people undoubtedly have a wide network of colleagues and graduate stu-

TABLE 10

Where Cited by Status

\begin{tabular}{|c|c|c|c|c|c|}
\hline Where Cited & $\begin{array}{c}\text { Faculty } \\
\text { No. }\end{array}$ & $\begin{array}{c}\text { Graduate } \\
\text { Students } \\
\text { No. }\end{array}$ & $\begin{array}{c}\text { Undergrad. } \\
\text { Students } \\
\text { No. }\end{array}$ & $\begin{array}{c}\text { Staff } \\
\text { No. }\end{array}$ & $\begin{array}{c}\text { Other } \\
\text { No. }\end{array}$ \\
\hline Article & 34 & 22 & 4 & 2 & 0 \\
\hline Book & 9 & 5 & 1 & 1 & 1 \\
\hline CD-ROM & 61 & 44 & 14 & 11 & 0 \\
\hline Index ${ }^{*}$ & 3 & 2 & 3 & 2 & 1 \\
\hline Online & 21 & 8 & 0 & 37 & 0 \\
\hline Print Index & 17 & 20 & 3 & 0 & 0 \\
\hline $\begin{array}{l}\text { Personal } \\
\text { Communication }\end{array}$ & 8 & 2 & 0 & 0 & 0 \\
\hline Other & 4 & 4 & 1 & 0 & 0 \\
\hline None Listed & 27 & 30 & 7 & 0 & 3 \\
\hline Total & 184 & 137 & 33 & 53 & 5 \\
\hline
\end{tabular}

"Index = index of unknown format. 
TABLE 11

BREAKDOWN BY YEAR AND SOURCE OF DOCUMENT

\begin{tabular}{lrrrrrrrr}
\hline \hline & \multicolumn{2}{c}{ Document Delivery } & \multicolumn{2}{c}{ Interlibrary Loan } & \multicolumn{2}{c}{ SUNY EXPRESS } & \multicolumn{2}{c}{ Unknown } \\
Time & No. & $\%$ & \multicolumn{1}{c}{ No. } & $\%$ & \multicolumn{1}{c}{ No. } & $\%$ & No. & $\%$ \\
\hline 1994 & 1 & 20 & 1 & 20 & 3 & 60 & 0 & 0 \\
$1984-93$ & 39 & 12 & 203 & 63 & 6 & 24 & 2 & 1 \\
$1974-83$ & 2 & 6 & 21 & 60 & 12 & 34 & 0 & 0 \\
$1793-1973$ & 0 & 0 & 45 & 88 & 5 & 10 & 1 & 2 \\
Total & 42 & 10 & 271 & 66 & 96 & 23 & 3 & 1 \\
\hline
\end{tabular}

dents who provide them with information about who is working on topics of interest to them. Neither graduate nor undergraduate students have the same kind of access to the "invisible college" and must therefore rely more heavily on library resources for information about what has been published. In addition, since Hallmark reports on citations gathered for articles that were published in 1991, many of the citations must have been identified in 1990 or before, given the time lag in researching, writing, and publishing. Since end-user searching of electronic bibliographic databases (both CD-ROM and online) was just becoming easily and widely available in the late 1980 s, it is possible that our figures reflect the rapid change in technology that was taking place during this time.

While faculty and students at the University at Albany seem to use the various methods of identifying journal articles at about the same rate, patrons who identified themselves as staff ( $13 \%$ of the requesters) relied disproportionately on online searches ( $70 \%$ of their requests). It is possible that this reflects grant support for online searching conducted by staff members in laboratories that support faculty research (see table 10).

\section{Source of Filled Requests}

The source used for obtaining documents through ILL, which was indicated on the forms by ILL staff, was analyzed for possible trends (see table 11). The most heavily used method was traditional ILL (66\%), followed by SUNY EXPRESS
(23\%). SUNY EXPRESS is an expedited delivery service for books and journal articles that are requested from one of the SUNY University Centers-Albany, Binghamton, Buffalo, and Stony Brook. It was initiated about 6 months into our study. Document delivery services accounted for only $10 \%$ of filled requests, but the library was just beginning to experiment with document delivery during the study period. In general, document delivery is used if copyright has been exceeded, if heavy volume makes document delivery more expedient, or if there is a real need to rush a particular request. If the study were repeated today, it would probably show an increased reliance on document delivery. For articles published between 1793 and 1973 (prior to the current 20 years), document delivery was not used, and SUNY EXPRESS was a minor source $(10 \%)$. For 1974-83, the use of SUNY EXPRESS jumped to $34 \%$, then leveled off at $24 \%$ for $1984-93$. In this most recent time period, ILL is the largest source $(60 \%)$ and document delivery increases only to $6 \%$. Document delivery at the time of the study did not seem to be very useful for older articles, most likely because these services tend not to have large retrospective collections.

\section{Cost/BENEFIT ANALYSIS}

Because there seems to be a far greater demand for occasional articles from a wide variety of journals rather than repeated demand for articles from a few titles, ILL should be a cost-effective and relatively efficient way of supplying infor- 
mation except in the cases of the few titles that were requested many times. Gossen and Irving (1995) and Kingma (1996) have recently investigated the economic efficiency of this arrangement. They showed that for titles that are infrequently used or very expensive, it is generally more cost effective to use ILL than to subscribe. Current prices for 209 of the 291 journals that were requested during 1993-94, were obtained. These titles accounted for 318 of the 412 requests. Many of the periodicals for which prices could not be found have been discontinued; others are irregular publications for which the price varies from year to year. The cost of subscribing to the 209 journals at current prices would have been $\$ 78,454$. Assuming that use would be the same if the periodical were on the shelf, the average cost per use of these 318 articles would have been $\$ 246.70$. Using the ARL/RLG average cost of $\$ 18.64$ for borrowing an item on ILL (Roche 1993), the cost of acquiring the same information via ILL would have been $\$ 5,928$, a considerable savings. Ferguson and Kehoe (1993) estimated the "fully loaded" ILL borrowing cost for articles in biology, physics, and electrical engineering to be $\$ 27$ and the cost for an article through document delivery to be $\$ 39$, including internal processing charges and the fees charged by the service. Using the higher figure, it would have cost $\$ 12,720$ to obtain the 318 articles. This is still far less expensive than it would have been to subscribe to those journals. While it can certainly be argued that patrons may not request articles on ILL that they might have found useful if they were in the library, a strong case can be made for the cost effectiveness of ILL for infrequently used titles. Journals must, of course, be evaluated on a title-by-title basis, because factors in addition to cost per use, such as availability via document delivery and centrality to mission, must be taken into account when making decisions to purchase a title or borrow it.

\section{Periodical Cancellations}

Libraries have been faced with increasing periodical subscription costs at a time when budgets are not keeping pace. This is especially true for science periodical titles. One of the results of this dilemma has been the decision to cancel journals. Two large periodical cancellation projects were carried out in the University Libraries in 1988 and 1992. Journal titles from the ILL data were compared to the 1988 and 1992 cancellation lists to determine whether titles that had been canceled had later been requested on ILL. Of the 688 titles canceled in 1988, only 6 titles (1\%) were requested a total of 8 times during our study. Of the 979 titles canceled in 1992 , only 2 titles were requested a total of 2 times; it is probable that not enough time had elapsed between the 1992 cancellations and our study for their effect to have really been noticed. It is clear that the science titles canceled in 1988 were not heavily requested by the science faculty, staff, or students during the year of the study.

A number of explanations for this are possible. First of all, it may be that these cancellations were wisely chosen, based on accurate use studies and careful deliberation. Alternatively, the faculty, staff, and students in the sciences may have had other, nonlibrary sources for getting copies of articles from the canceled journals. It is also possible that information published in those journals was not important enough to their research to overcome the inconvenience and time delay involved in getting articles through ILL. Most likely, it is a combination of all of these factors.

\section{Conclusrons}

There are several findings that emerge from our data:

1. There were differences among scientists by discipline in the amount of use made of ILL as a means of obtaining periodical articles. Two departments, biology and chemistry, accounted for $74 \%$ of the total use. These differences might be magnified (or diminished) in a longitudinal study of ILL use. One solution may not suit all disciplines, and different approaches could be taken in building collections and providing access 
to information in different disciplines.

2. ILL is used by researchers to obtain only 1 or 2 articles as well as by a few individual researcher to get large numbers of journal articles. ILL requests should be monitored to make sure that the same title isn't being requested many times, in which case a decision to buy the title might be appropriate. We found that the vast majority $(94 \%)$ of requests were for titles that were used only once or twice. Relying on interlibrary lending for these documents is a cost-effective way of providing such information.

3 . While most requests were for articles that had been written within the tenyear period before the study, $21 \%$ of the requests were for older materials in spite of the supposed emphasis in the sciences on current materials. If requests from the humanities and social sciences had been analyzed, the percentage of older materials might have been even greater. Thus, it is not only current information that is in demand.

4. While researchers use electronic indexing services (CD-ROM and online) to generate a high percentage of their requests, there is still considerable use of traditional resources, such as print indexes and personal communication, as sources of information about journal articles. Traditional print sources are particularly important for older information and should be maintained in reference collections for the foreseeable future.

\section{FURTher Study}

Information about who uses ILL and what they are requesting can provide data on the use of journal titles not owned by the library and the variation in use among disciplines. This information can be useful in making management decisions about periodical collections and resource sharing among libraries. To add to this picture of ILL use by scientists at the University at Albany, we hope to do a similar study of their requests for books, and to interview them about their satisfaction with library resources and services and alternative methods used to access information. A more comprehensive and thus more informative picture of ILL use in the sciences will emerge if other libraries carry out similar studies.

\section{WORKS CITED}

Barschall, Henry H. 1985. The cost-effectiveness of physics journals. Physics today.

Brown, Charles Harvey. 1956. Scientific serials: Characteristics and lists and most cited publications in mathematics, physics, chemistry, geology, physiology, botany, zoology, and entomology. ACRL monograph no. 16. Chicago: Assoc. of College and Reference Libraries.

Devin, Robin B. 1989. Who's using what? Library acquisitions: Practice \& theory 13: 167-170.

Ferguson, Anthony W., and Kathleen Kehoe. 1993. Access vs. ownership: What is most cost-effective in the sciences? Journal of library administration 19, no. 2: 89-99.

Gossen, Eleanor, and Suzanne Irving. 1995. Ownership versus access and low-use periodical titles, Library resources \& technical services 39: 43-52.

Hallmark, Julie, 1994. Scientists' access and retrieval of references cited in their recent journal articles. College \& research libraries 55: 199-208.

Hamaker, Charles A. 1989. Costs and the serials information chain: Containing the impact on library budgets. Journal of library administration 19, no. 2: 101-23.

- 1994. Re-designing serials collections. Journal of library administration 20 , no. 1: $37-47$

Herzog, Kate. 1993. CRL journal use study data: A review of the methodologies, some preliminary results, and some policy issues. March 29. University at Buffalo, State University of New York.

Ketcham, Lee, and Kathleen Born. 1996. Projecting the electronic revolution while budgeting for the status quo. Library journal 121, no. 7: 45-51.

Kingma, Bruce R. 1996. Economics of access versus ownership: The costs and benefits of access to scholarly articles via ILL and journal subscriptions. New York: Haworth.

Roche, Marilyn M. 1993. ARL/RLG ILL cost study: A joint effort by the Association of Research Libraries and the Research Libraries Group. Washington, D.C.: The Association. 